\title{
WAYRA WASI: LA CASA DEL VIENTO. MEMORIAS Y SIGNI- FICADOS DE UNA CUEVA AL EXTREMO SUR DEL DOMINIO INKA (CHADA-CULITRÍN, REGIÓN METROPOLITANA, CHILE)
}

\author{
Wayra Wasi: The House of the Wind. Memories and Meanings of a Cave at the \\ Southern End of The Inka Domain (Chada-Culitrin, Metropolitan Region, Chile)
}

\section{JUAN FRANCISCO ECHEVERRÍA*}

\section{Resumen}

Según la crónica de Gerónimo de Bibar, cerca de la Angostura de Paine (Chile) se encontraba una cueva adorada por la cultura Inka, por donde salía el viento con fuerza. En este artículo se presenta una revisión bibliográfica de lo que se ha escrito sobre esta cueva, hoy destruida, y se presentan los resultados de una investigación etnográfica con el objetivo de mostrar las múltiples memorias asociadas a este espacio, además de interpretar sus posibles significados. De esta manera, se presentan las posibilidades de estudiar un sitio de difícil acceso arqueológico, pero de un alto valor simbólico, a través de una metodología interdisciplinaria. Al mismo tiempo, se introduce un tópico escasamente trabajado en la etnohistoria y arqueología chilena, el de los oráculos andinos, como una interpretación posible de la cueva del viento, ubicada en el extremo sur del Tawantinsuyu.

Palabras clave: Chada; oráculos andinos; Wayra Wasi; Tawantinsuyu; memoria.

\section{Abstract}

According to Geronimo de Bibar's chronicle, near the Angostura de Paine (Chile), was located a cave adored by the Inka culture, where the wind came out strongly. In this article, it is presented a bibliographic review of what has been written about the cave now destroyed and the results of an ethnographic investigation with the aim of showing the multiple memories associated to this place, as well as interpreting their possible meanings. In this way, through an interdisciplinary methodology the possibilities of studying such a hard site for archaeological excavations but of high symbolic value are presented. At the same time, is introduced a topic scarcely worked on in Chilean ethno-history and archaeology, that of the Andean oracles, as a possible and accurate interpretation of the cave of the wind, located at the southern end of the Tawantinsuyu.

Keywords: Chada; Andean oracles; Wayra Wasi; Tawantinsuyu; memory.

\footnotetext{
* Lic. en Historia, Lic. en Educación y Profesor de Educación Media. Independiente, Chile. La investigación se desarrolló en primera instancia en el curso "Recordar, registrar e historiar memorias indígenas. Propuesta de ejercicios de investigación”, a cargo de la profesora María Carolina Odone, Pontificia Universidad Católica, 2017. Posteriormente se continuó investigando de manera independiente. Correo-e: jfecheverria@uc.cl
} 


\section{Introducción}

En la Crónica y relación copiosa y verdadera de los reynos de Chile, terminada en 1558, Gerónimo de Bibar escribió que en una sierra ubicada al este de la actual Angostura de Paine, al sur de la Región Metropolitana de Chile, el pueblo Inka encontró una cueva por la que salía viento con mucha fuerza. Al verla, los indígenas cuzqueños se alegraron "porque decían que habían hallado guayravaci, que es tanto como si dijese 'la casa del viento"' (Bibar, 1952, p. 138). Esta es la única fuente histórica que hace referencia directa a Wayra Wasi y ese fue el punto inicial de una investigación realizada en 2017 y 2018, que tuvo por objetivo averiguar qué había sido de ese espacio en la actualidad y dilucidar si aún existían memorias asociadas a la cueva entre los vecinos del sector.

En este artículo se presentará una revisión bibliográfica sobre lo que se ha escrito respecto a Wayra Wasi y se presentarán los resultados de la etnografía realizada en sus localidades aledañas $^{1}$ para dar cuenta de las distintas memorias asociadas a la cueva y, finalmente, proponer una hipótesis sobre su posible significado simbólico en el contexto de la anexión de los valles centrales de Chile al Tawantinsuyu, el "imperio" Inka.

\section{Metodología}

El método propuesto para esta investigación tuvo un enfoque interdisciplinario que combinó elementos propios de la historia y la antropología. De la primera disciplina se tomó como referente teórico y metodológico el enfoque microhistórico, que permite observar con mayor atención y detenimiento ciertos elementos que, por lo general, pueden pasar desapercibidos en las perspectivas globales (Man, 2013). Así, con una mirada microespacial, se analizaron en profundidad las fuentes primarias y secundarias existentes en relación con la ocupación Inka de las zonas aledañas a la cueva del viento para buscar información que pudiera dar pistas sobre su significado y la extensión de este a otros espacios similares. Si bien desde la microhistoria se sostiene que las conclusiones de un caso específico no pueden ser generalizadas a la totalidad del proceso estudiado, sí es posible apuntar que los casos particulares, "límites", también pueden ser representativos (Ginzburg, 2008; Echeverría \& Bravo, 2019).

Tal como la microhistoria propuso, desde sus inicios, vincular el método histórico con el trabajo de campo propio de la antropología, en esta investigación se utilizó una metodología etnográfica y el estudio de memorias. La perspectiva etnográfica fue entendida como un "estar ahí", en el espacio de interés, para escuchar y estar atento "multisensorialmente" a los sucesos del lugar y su gente; es decir, tener todos los sentidos puestos en la aprehensión del entorno para describirlo de manera densa, analizarlo teóricamente y recopilar testimonios orales que permitan entender las dinámicas de sus grupos humanos (Geertz, 1992; Curatola, 2012; Echeverría, 2019).

Siguiendo estos principios, durante el segundo semestre de 2017 se realizaron numerosas visitas a las localidades de Chada, Culitrín y, en menor medida, Hospital (Colonia Kennedy), en la comuna de Paine, Región Metropolitana. Además, en 2018 se realizó una segunda etnografía de nueve meses junto a la antropóloga Carla Bravo, que estuvo enfocada en la historia reciente de Chada. En el primer 
trabajo en terreno, que giró en torno a Wayra Wasi, se realizaron ocho entrevistas, de las cuales tres contenían información relacionada con la cueva. Dos de estas tres entrevistas semiestructuradas se hicieron en parejas, por lo cual se recopilaron los testimonios de cinco personas, de entre 55 y 75 años: Esteban Fuentes, de Culitrín; Óscar Pinto, de Colonia Kennedy; Néstor Soto, Cristián Sepúlveda y Miguel Caviere, de Chada². Para ello se contó con los consentimientos informados respectivos $y$, posteriormente, con su aprobación de un escrito preliminar del presente artículo.

Los testimonios fueron estudiados como "memorias individuales", es decir, como relatos del pasado mediados por los recuerdos y olvidos de cada persona, a través de los cuales es posible acceder a situaciones pretéritas, pero teniendo en cuenta los matices de cada entrevistado, puesto que cada uno reconstruye el pasado desde sus marcos de referencias contemporáneos y personales (Ricoeur, 2004; Stern, 2009; Echeverría, 2019).

\section{Chada, un espacio relevante}

La cueva denominada Wayra Wasi por el Inka, según Bibar, se encuentra ubicada en las proximidades del actual sector de Culitrín, junto a la localidad de Chada. Mientras que el primer poblado casi no ha sido estudiado arqueológicamente, el segundo ha llamado la atención del mundo académico por lo menos desde 1994, cuando se hicieron las primeras aproximaciones arqueológicas, siguiendo lo escrito por Bibar (Stehberg, Planella \&
Niemeyer, 1998). Chada, actualmente un valle rural, formó parte de la zona austral del Kollasuyu, la región meridional del Tawantinsuyu. A partir de la lectura de los trabajos arqueológicos y etnohistóricos sobre el lugar, es posible sostener que fue un sector de gran importancia para las poblaciones prehispánicas en, por lo menos, tres ámbitos: (i) como un lugar de asentamiento, (ii) como un punto de control estratégico y (iii) como un espacio religioso.

El primero de estos tres puntos hace referencia a una ocupación de larga data en el valle. La zona del río Angostura y sus afluentes fue ocupada, al menos desde el año 300 d.C., por miembros de la denominada cultura Llolleo y, a partir del 900 d.C., por grupos Aconcagua (Toro, Olea, Gallardo \& Castillo, 2015a). Estos últimos poblaron Chada hasta la Ilegada del Inka y luego convivieron con él, como se deduce de los dos sitios habitacionales hallados en el sector: Turbinas 1 y Turbinas 2. Estos asentamientos pueden considerarse como parte de un caserío o pueblo habitado desde 1030 d.C. (Stehberg et al., 1998).

Es una realidad que gran parte del valle fue habitado por poblaciones Llolleo, Aconcagua $y$, posiblemente, Bato, en zonas que no han sido estudiadas aún (Luis Cornejo, comunicación personal, 26 de septiembre de 2018). De hecho, nuevas prospecciones realizadas en 2019 a raíz de esta investigación, junto al arqueólogo Nicolás Ruano, indican que la ocupación Aconcagua habría sido muy relevante en el valle y que posiblemente existen sitios habitacionales y funerarios que aún permanecen sin excavar. 
Figura 1: a. Fragmentería cerámica hallada en Chada, ejemplo de lo que los agricultores encuentran con frecuencia. b. Cerámica proveniente del sitio habitacional Aconcagua en Chada, Período Agroalfarero Intermedio Tardío. c. Cerámica diaguita-inka, obtenida al interior del sitio Ruinas de Chada, Período Agroalfarero Tardío.

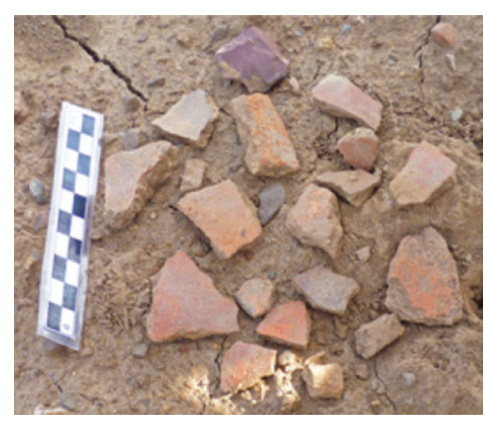

a.

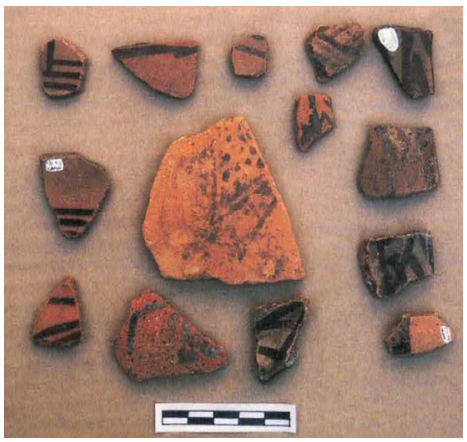

b.

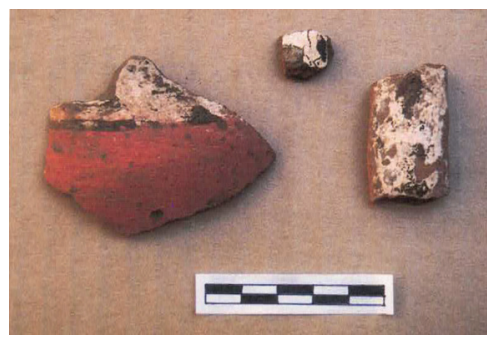

C.

Fuente: a. Toro, Olea, Gallardo \& Castillo (2015b). b. y c. Stehberg et al. (1998).

Cuando este territorio y su población local fueron incorporados al Tawantinsuyu, Chada pasó a ser entendida desde una perspectiva político-militar como un sector de gran relevancia estratégica para la expansión Inka hacia el sur. Esta zona se habría convertido en una suerte de frontera cultural entre los grupos Aconcagua y otros que se opusieron con mayor fuerza a los cuzqueños y que, por lo mismo, fueron denominados, despectivamente, purun auca, noción quechua que destaca el carácter subversivo y, por lo tanto, "salvaje" de estos grupos. De la hispanización de este término surgiría el exónimo "promaucaes" (Stehberg \& Planella, 1998; Manríquez, 2002).

Ante esta situación adversa, el Inka tuvo que desplegar todo un mecanismo defensivo que le asegurara el control del paso que cruzaba el cordón de Angostura desde el valle de Chada hacia el sur. Por lo que no solo consolidaron su red vial, el Qhapaq Ñan, sino que también la resguardaron mediante la construcción de, al menos, un reducto fortificado de cumbre (Stehberg, 2013). Así se evidencia en el cerro El Peral, un poco más al norte de Chada, camino a Huelquén, desde donde es posible vigilar todo el valle en caso de algún ataque (ver Figura 2). Con la construcción de este reducto fortificado, el Inka habría buscado defender y controlar el sector "para garantizar la seguridad de los mitimaes y aliados locales y para asegurar la futura ampliación del dominio incaico a las tierras y poblaciones Promaucaes", más al sur (Stehberg, 2013, p. 131).

Ahora bien, si el control Inka de la zona central de Chile se hizo de manera directa o a través de poblaciones aledañas es algo que aún no está esclarecido del todo. Mientras algunos autores se inclinan por pensar que el control efectivo del territorio estuvo a mano de la población diaguita antes que la Inka (Silva, 1985; Stehberg, 1995; Cornejo, 2001, 2016; Cornejo 
\& Saavedra, 2018) y otros postulan que estos grupos participaron más bien como un apoyo para la expansión cuzqueña, de forma más matizada y heterogénea (Stehberg et al., 1998; Stehberg \& Sotomayor, 2012; Caro, 2017), hay quienes cuestionan la participación diaguita en el control de la población local (Pavlovic, Troncoso, Sánchez \& Pascual, 2012; Pavlovic, Sánchez, Pascual, Martínez, Cortés, Dávila \& La Mura, 2019).
Sea como fuere, teniendo en cuenta las particularidades de cada cuenca de la zona central, la mayoría de los autores pareciera concordar en que primaron las categorías de la cosmovisión cuzqueña en el control y el ordenamiento de la población local en vez de las propiamente diaguitas, producto de la negociación entre los grupos locales y extranjeros (Stehberg \& Sotomayor, 2012; Moyano \& Bustamante, 2013; Moyano, 2016, 2018; Stehberg, Gatica \& Torrijos, 2018; Pascual, Martínez, Pavlovic, Dávila, Cortés, Albán \& Fuenzalida, 2018; Pavlovic et al., 2019).

Figura 2: Ubicación referencial de los sitios arqueológicos en Chada y sus alrededores.

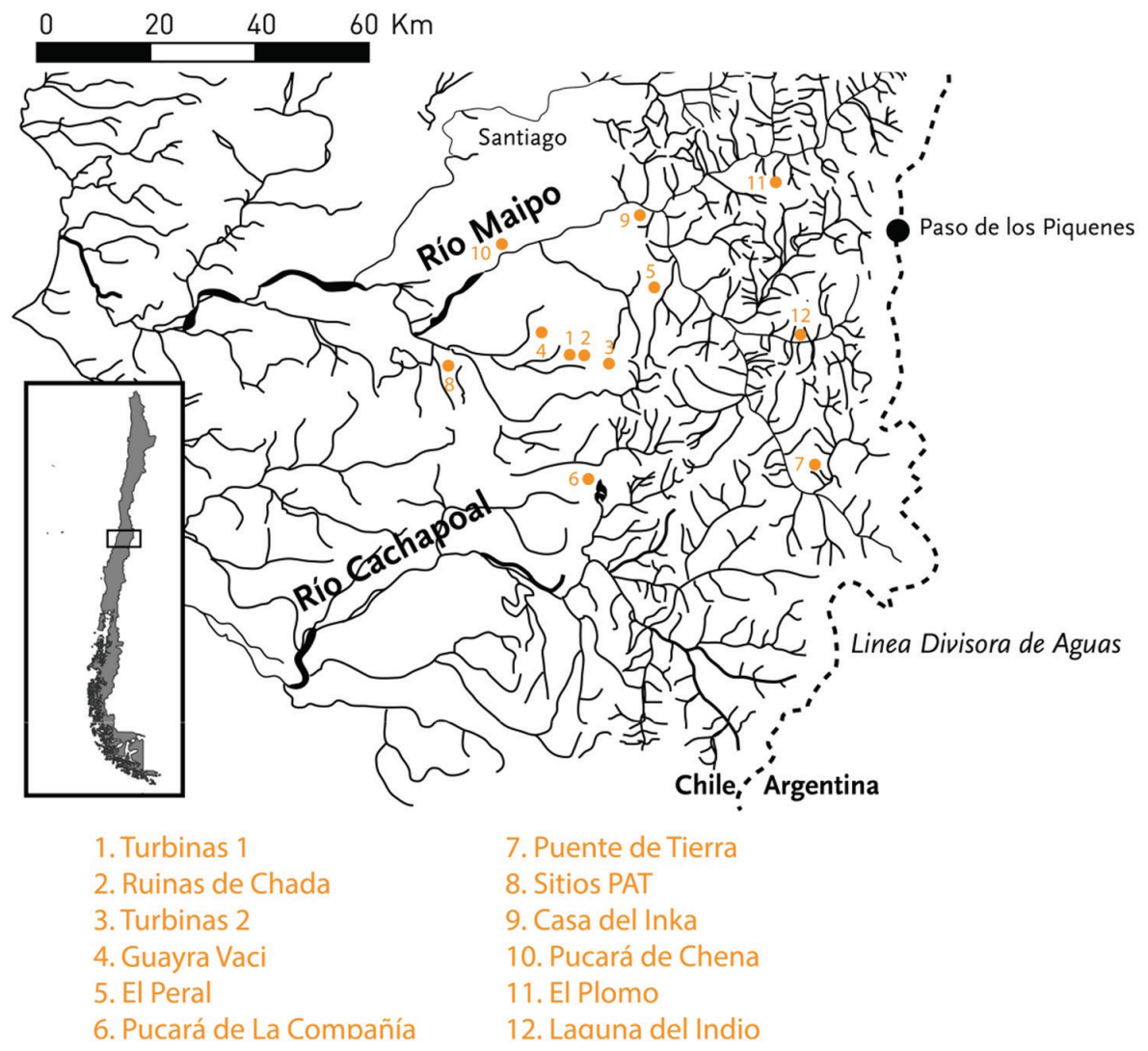

Fuente: Editado de Toro et al. (2015a), a su vez modificado del original en Cornejo \& Sanhueza (2011). 
El control del sector, sin embargo, no podía hacerse solamente desde una perspectiva militar. Por el contrario, la ocupación Inka era consumada a través de un dominio religioso, tal como ocurrió en las cuencas de los ríos Mapocho y Maipo, donde la hipótesis de un enfrentamiento violento entre el Tawantinsuyu y las poblaciones locales está cada vez más descartada (Pavlovic et al., 2019). En cambio, las investigaciones actuales proponen que otros mecanismos simbólicos, como los "banquetes políticos", que eran festines organizados por las elites para afianzar su dominio en las regiones conquistadas, y la sacralización de los espacios geográficos a partir de la cosmovisión cuzqueña habrían sido utilizados en el extremo sur del Kollasuyu para controlar a la población (Dillehay, 2003; Stehberg et al., 2018; Cornejo \& Saavedra, 2018; Pavlovic et al., 2019).

En el caso de Chada, esto es particularmente evidente, puesto que el valle se habría transformado en una de las últimas fronteras religiosas al sur del Tawantinsuyu (Stehberg, 2013). Justo en medio de los poblados Aconcagua Turbinas 1 y 2 , y sobre la cima de una loma doble de baja altura, fue construida una de las edificaciones inkaicas más singulares arquitectónicamente del territorio chileno, denominada actualmente Ruinas de Chada. Así lo entendieron los arqueólogos que comenzaron a excavarlas, Rubén Stehberg, María Teresa Planella y Hans Niemeyer, quienes reconocieron, en su estructura de dos muros concéntricos, nociones de dualidad, tri y cuatripartición, propios del Tawantinsuyu. Las dataciones cerámicas del sitio fueron en torno al 1475 d.C., lo que concuerda con las fechas tradicionales de la ocupación Inka de la región (Stehberg et al., 1998). No obstante, nuevas investigaciones señalan que este proceso se habría iniciado posiblemente a principios del siglo $\mathrm{XV}$, por lo cual la construcción y ocupación de las Ruinas de Chada podría haberse iniciado décadas antes (Cornejo, 2014; Marsh, 2016).

En un principio, el uso del complejo arquitectónico Ruinas de Chada fue asociado al control de la población local, la producción agrícola y el posible albergue de funcionarios del Inka (Planella \& Stehberg, 1997; Silva, Silva, La Mura, Fuenzalida \& Brinck, 2017), pero con el tiempo esta idea se ha ido complejizando. Si bien el propio Stehberg (2013) destacó posteriormente el carácter sagrado del sitio denominándolo $w_{k} a^{3}$, no fue sino a partir de los estudios arqueoastronómicos de Nicolás Ruano que la función del recinto amurallado comenzó a esclarecerse. Su estudio, realizado en 2010 y 2011, comprobó la posibilidad de hacer observaciones astronómicas desde el sitio utilizando los cerros de la localidad como marcadores naturales de horizonte. Tras estudiar el recorrido del sol en los solsticios y equinoccios desde las Ruinas, Ruano (2012) concluyó que estas:

[...] fueron construidas con un propósito simbólico, al servir como un lugar de observación de eventos astronómicos, en los cuales el Inca regente o su representante contemplaba la circulación del Sol por la bóveda celeste, y lograba identificar fechas precisas gracias a los marcadores naturales de horizonte [...].

Ahora bien, postulamos que cuando el Inca o su representante reconocía la aproximación de una fecha determinada, desarrollaba rituales en los que invitaba a los "no-inca" al interior de las Ruinas de Chada, para que contemplaran junto a él, los ortos y ocasos del Sol, tras un horizonte conocido; probablemente los invitados se posicionaban al interior del sitio según su jerarquía [...]. Esta invitación y celebración ritual traía consigo una unión simbólica de los grupos locales (Aconcagua) con el Inca, y su correspondiente control (p. 212). 
De esta manera, las Ruinas de Chada habrían tenido un papel fundamental en la instalación y la negociación del poder simbólico cuzqueño $y$, posiblemente, diaguita-inka (ver Figura 1. c.) sobre la población local a través de la observación solar y sus ritos asociados (ver Figura 3). Esto se ha visto reforzado por las últimas investigaciones de Pavlovic et al. (2019), cuyas conclusiones sostienen que en los complejos arquitectónicos de Chada, Chena y, posiblemente, Collipeumo se habrían realizado prácticas de adoración tanto a las grandes cumbres del frente andino, sacralizadas por el Inka, como a las waka locales de los valles. En esos eventos, "la convocatoria y el agasajo a las poblaciones locales generaba una deuda, un compromiso, que en el marco de una reciprocidad asimétrica hacía plausible a los representantes del Tawantinsuyu contar con su colaboración para cumplir sus propósitos en la zona" (p. 74).

Con todo lo anterior, la relevancia prehispánica de Chada es indiscutida. A tal punto que Rubén Stehberg ha escrito sobre el valle: "no dudamos en postular este sector como uno de los puntos de mayor significación dentro del proceso expansivo incaico de Chile central" (2013, p. 145).

Figura 3: a. Levantamiento topográfico general del sitio Ruinas de Chada y Turbinas 1. b. Plano topográfico de las Ruinas de Chada. c. Observaciones de las puestas de sol en los solsticios y equinoccios desde el ushnu, ubicado al centro del complejo arquitectónico de Chada.

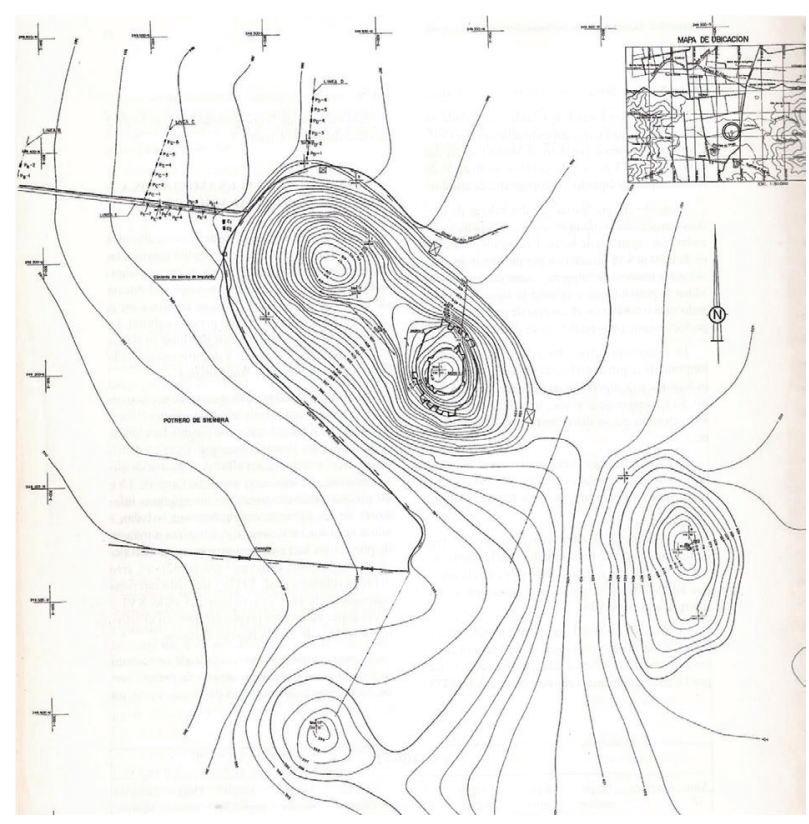

a.

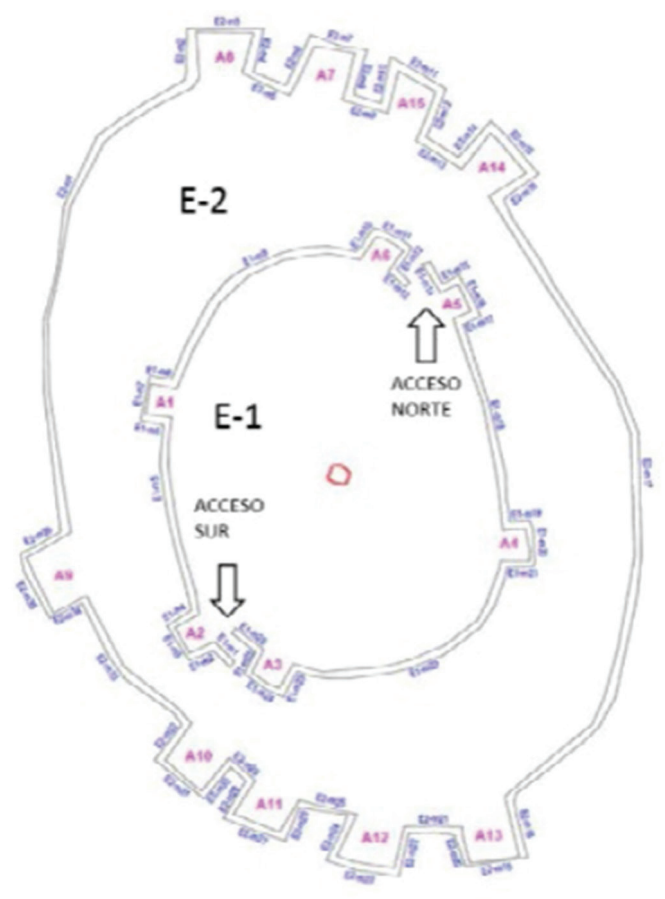

b. 


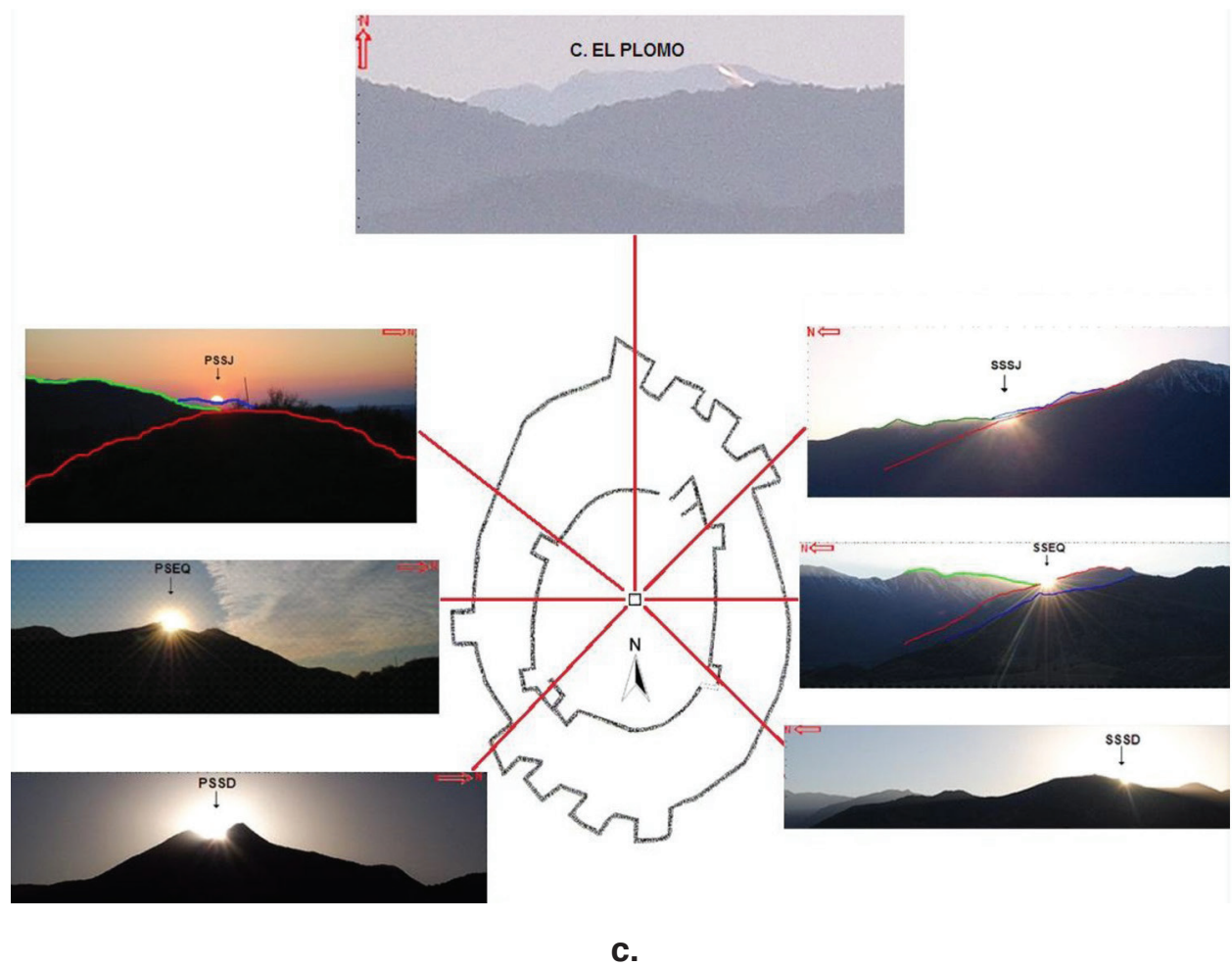

Fuentes: a. Stehberg et al. (1998). b. Pavlovic et al. (2019), a partir del plano topográfico de Roberto Izaurieta. c. Ruano (2012).

Ahora bien, si la existencia del complejo arquitectónico Ruinas de Chada ha sido asociada a la observación de fenómenos solares y posiblemente lunares (Moyano, 2016, 2018), y también a la adoración de waka locales, cabe preguntarse cuál espacio o entidad sagrada era adorada en ese sector tan relevante dentro del Kollasuyu.

\section{Wayra Wasi}

Wasi quiere decir, en quechua, "casa" y wayra, "viento", pero para el mundo andino este último término tiene un significado más profundo. El viento de las tempestades y las lluvias estaba asociado a la poderosa divinidad Illapa (Manríquez, 1999) y a Wari, "un dios agrícola por excelencia y también un héroe civilizador, era el viento que se desplazaba a gran velocidad y visita el mundo" (Rostworowski, 2007, p. 51). Si bien la devoción a esta última divinidad habría sido mayor entre los 600 y 1000 a.C., su culto se prolongó hasta el s. XVII (Yauri, 2016). Igualmente, el viento era identificado con Wayra Tata, divinidad que origina y produce los vientos, lanza huracanes y habita en las cumbres de los cerros o en las profundidades de los abismos (Cáceres, 2006; Medinacelli, 2012; Olivera, 2016). 
A diferencia de muchos estudios etnohistóricos sobre las waka o lugares adorados por el Inka, para el caso que aquí se presenta solo se ha encontrado, hasta el momento, una fuente escrita que menciona explícitamente la existencia de Wayra Wasi, entidad posiblemente venerada en Chada-Culitrín. Es por eso que la contextualización del momento histórico realizada más arriba a partir de la literatura disponible resulta tan necesaria desde una perspectiva metodológica. No obstante, esta aproximación bibliográfica es insuficiente para determinar la existencia de un espacio y aún más sus posibles significados, por lo cual se plantea el método etnográfico como una forma de complementar la información disponible y buscar diferentes pistas dentro del espacio local.

La única referencia colonial a Wayra Wasi, es la siguiente:

Está esta provincia de los Pormocaes, que comienza de siete leguas de la ciudad de Santiago, que es una angostura y ansí le llaman los españoles estos cerros que hacen una angostura. Aquí llegaron los Incas cuando vinieron a conquistar esta tierra, y de aquí adelante no pasaron. En una sierra de una parte de angostura hacia la cordillera toparon una boca y cueva, la cual está hoy en día y estará, y de ella sale viento y aun bien recio. Como los Incas lo vieron fueron muy contentos porque decían que habían hallado guayravaci, que es tanto como si dijese "la casa del viento." Allí poblaron un pueblo, los cuales cimientos están hoy en día, y no digo de ellos por estar tan arruinados (Bibar, 1952, p. 138).

Stehberg y Planella (1998) sostienen que el pueblo señalado por Bibar, cuyos cimientos ya en el siglo XVI estaban arruinados, correspondería a las Ruinas de Chada. Pero, ¿qué sucedió con esta cueva, que tras ser hallada por el Inka habría motivado la construcción del complejo arquitectónico? ¿Hasta qué punto son ciertas las palabras del cronista? Los primeros en realizar un acercamiento etnográfico en búsqueda del sitio fueron los arqueólogos mencionados, cuyas prospecciones "permitieron el hallazgo de la boca y cueva 'guayra vaci', mencionada por Bibar. Se ubica a unos $4 \mathrm{~km}$ al $W$ de las ruinas de Chada, en la falda nororiente del cerro Challay, siendo visible el sitio desde las ruinas" (Stehberg \& Planella, 1998, p. 167). Es decir, el sitio se encontraba aproximadamente entre Chada y Culitrín. Asimismo, los autores concluyeron que la "casa del viento" constaba de:

[...] dos bocas o cavernas en cada uno de sus extremos, denominadas cueva de La Vieja y cueva del Cura, respectivamente, y corresponderían a restos de un cauce seco, por el cual pudo circular fuerte viento que dio origen al comentario de Bibar. Hoy la cueva del Cura ha sido destruida por los lugareños, quienes consideraban que 'se tragaba a la gente' (Stehberg \& Planella, 1998, p. 167).

Este fragmento entrega información muy sugerente sobre la cueva, como el hecho de que había sido destruida o la explicación de que el viento salía de ella debido a su estructura de túnel. Ahora bien, se debe enfatizar que, tal como se señaló, los testimonios orales son relatos dúctiles y en gran medida individuales, por lo cual la información que los arqueólogos obtuvieron en la década de 1990 es solo una de las múltiples memorias asociadas a esta cueva y, posiblemente, la primera documentada: Wayra Wasi interpretada como la "cueva de la vieja" y la "del cura", destruida por tragarse a la gente. Un tercer arqueólogo, por su parte, dio cuenta de la subjetividad de las memorias al momento de visitar el sitio y recabar más información. Ruano (2012) determinó empíricamente que la cueva había sido destruida con dinamita, pero sin un motivo claro, producto de los múltiples relatos asociados a este evento: 
Guayra Vaci, es conocida oralmente por algunos lugareños, ya que dicen que nunca la han visto pero que han escuchado hablar de ella, y que se encontraría "por allá cerca del puente Culitrín", a la que denominan como "la cueva del cura" y otros como "la cueva del padre", cuyos nombres lo bautizaron (según lo que cuentan) debido a un sacerdote que hace mucho tiempo vivía en la zona y que realizaba visitas periódicas a la cueva, algunos dicen que "el cura se volvió loco por meterse a la cueva y por eso la dinamitaron", otras personas dicen que la razón de su destrucción se debe a que los animales que pastaban en el lugar entraban al interior de la cueva a parir y luego era muy difícil sacarlos con sus crías, pero también hay otros que dicen que hace muchos años iban a esconderse los hombres y a "portarse mal" debido a que en su interior se reunían a jugar al "monte", que era un juego prohibido en aquellos años, donde se realizaban apuestas en el que se aceptaba de todo. Esta última opción se reforzaría con la evidencia de los restos de botellas de vidrio hallados cercanos a la cueva (pp. 348-349).

Estos diferentes testimonios demuestran las múltiples reinterpretaciones y resignificaciones del espacio hallado por el Inka, entendido en ese entonces como un posible lugar de veneración, y que siglos después sería percibido como un espacio de locura, nacimiento de animales o excesos.

A estos relatos se les puede sumar un último testimonio recabado con anterioridad, esta vez por Álex López. Jorge Vargas, quien viajaba a Culitrín en su niñez, fue entrevistado para el capítulo audiovisual de López sobre la "cueva de Culitrín", donde hizo alusión a sus memorias sobre Wayra Wasi. Vargas relata que durante los años 1945 y 1946 había visitado ese espacio, conocido como la "cueva del padre", porque se decía que un sacerdote había vivido ahí como anacoreta. "Y también se decía que ahí había pasado Manuel Rodríguez, correteando hacia el sur. E incluso había un mapa del geográfico militar donde salía redondito, y decía 'cueva del padre'. No he encon- trado ahora este mapa, porque lo presté" (López, 2015). Luego continúa diciendo:

\begin{abstract}
Y Bibar la describe, y nosotros pensando siempre en cosas misteriosas y en tesoros, suponíamos cuando ya leímos la cueva, cuando ya leíamos a Bibar, suponíamos que ahí por el viento podía haber estos hornos de fundiciones, estos hornos de fundición, donde los inkas fundían el oro que sacaban (López, 2015).
\end{abstract}

De esta manera, nuevamente se identifica a Wayra Wasi con la cueva del padre, pero se incluyen elementos nuevos, como la figura de Manuel Rodríguez, considerado héroe patrio, y la asociación del espacio con riquezas extraídas por el Inka. Asimismo, se revela un nuevo tipo de memoria que guarda estrecha relación con uno de los testimonios recopilados en la etapa etnográfica del presente estudio, que fue denominado como "memoria mixta". Esta hace referencia a la mezcla o simbiosis entre lo que la gente ha leído sobre la cueva, es decir, una memoria construida no desde el relato oral, y las interpretaciones que dan a esa lectura. En otras palabras, algunas personas dicen conocer la cueva del viento porque han leído la construcción que han hecho de ella los relatos históricos, como Vargas con Bibar. Sin embargo, al llevar eso que saben a la realidad misma del espacio de Chada-Culitrín, sacan sus propias conclusiones, que no tienen relación necesariamente con lo que se ha escrito sobre la cueva, sino con cosas que ellos saben o suponen. Un ejemplo de ello es el siguiente fragmento de una de las entrevistas realizadas:

Guayra vaci se borró en el año 73 por los militares. Era supuestamente una cueva donde pasaba el viento, a través de ella, como cuando corre viento, como que silbaba. Pero a la vez también habían vestigios donde los indígenas sacaban mineral de esa cueva, porque allá a los pies del cerro [sic] había una salida por allá donde había unas piedras que están por donde echa- 
ban, derretían el material y lo' están los surcos de una piedra. $Y$ eso don Washington Soto ${ }^{4}$ la vio esa piedra; cuando salía a recorrer con los alumnos de Chada [...]. ¿Cómo se llamaba esa parte... la piedra esa? ¿Piedra del viento? ¿La cueva del...? ¡La casa del viento! La casa del viento. La casa del viento, guayra vaci (C. Sepúlveda \& M. Caviere, 2017. En cursiva los comentarios de Miguel Caviere y sin ella los de Cristián Sepúlveda).

A la pregunta sobre cómo sabía que llamaban "guayra vaci" a la cueva, Cristián Sepúlveda, jefe de la comunidad de regantes de Chada, contestó:

Por los escritos de Bibar, escribano español, se refiere a la casa del viento por lo mismo de los indígenas de la época del 1600, donde se hablaba de la casa del viento [...]. Era una creencia de que nacía el viento ahí. Bueno pue', es un sector natural de no sé si la temperatura cálida que nosotros tenemos un... el sector cálido con el aire frío hace que se aparezca como brisa permanente [...] por eso la llamaban la casa del viento (C. Sepúlveda \& M. Caviere, 2017).

En el contenido de esta memoria se puede apreciar una reinterpretación de la lectura de Gerónimo de Bibar ${ }^{5}$. En esta, Cristián Sepúlveda toma lo que dice la fuente, lo acepta como cierto y lo vincula a los hallazgos que otros vecinos han hecho, los surcos de una piedra que podrían indicar extracción minera, y a un fenómeno climático propio del sector, que repite durante la entrevista para explicar el "nacimiento" del viento, que recoge del escrito de Bibar. Asimismo, en este testimonio surge nuevamente la destrucción de Wayra Wasi, atribuida esta vez al actuar de las Fuerzas Armadas en 1973, tal como había señalado un grupo de arqueólogos previamente (Toro et al., 2015a, 2015b). Más allá de que la fecha sea exacta o no, hace referencia al período de la dictadura que inició en Chile con el golpe de Estado de 1973. A partir del cruce de infor- mación obtenida en el trabajo etnográfico y las entrevistas, todo pareciera indicar que fue durante esta etapa de la historia de Chile que se dinamitó la "casa del viento" y se destruyó, con ello, un patrimonio invaluable para la comunidad y una fuente importantísima de información para la reconstrucción del pasado del sector y de la ocupación Inka de la zona central del país.

Además del tipo de memoria mixta ya descrita, en las visitas a terreno se identificó una última memoria individual. Esta surgió de lo que un locatario, Néstor Soto, escuchó de sus vecinos, combinado, posiblemente, con su propia subjetividad. Es decir, es un tipo de memoria que tiene más relación con la oralidad y sus transformaciones que con lo que se ha escrito sobre Wayra Wasi. El entrevistado, ante la pregunta de cómo llamaban a la cueva, contestó:

El chiflón del diablo, porque corría viento ahí. Los indígenas lo llamaban chiflón del diablo, [...] era una caverna no más po', que salía acá al otro lado, a Culitrín, frente a Culitrín más o menos salía. Y le llamaban el chiflón del diablo porque corría viento y bufaba como toro (N. Soto, 2017).

Esta última memoria sería, entonces, propia de Chada, o al menos propia del entrevistado, construida mediante una reinterpretación de relatos orales de lo que "dicen los señores mismos de acá de Chada" sobre la "caverna" (N. Soto, 2017) y que asocia la figura del diablo y los bufidos de un toro con narraciones indígenas.

A partir de las múltiples interpretaciones existentes sobre la cueva del viento, recopiladas en terreno por Stehberg, Planella, Ruano, López y la presente investigación, es posible concluir que: 
1. Wayra Wasi fue una cueva que no solo existió, sino que permanece viva en los recuerdos de los pobladores de Chada y Culitrín.

2. Los significados asociados desde el presente a la antigua cueva son múltiples, diversos, y dependen, en gran medida, de las subjetividades de cada entrevistado.

3. Al menos en tres testimonios recopilados con anterioridad se asoció a Wayra Wasicon la llamada "cueva del padre" o "del cura", aunque durante la investigación en terreno no se encontraron memorias similares.

4. Stehberg y Planella plantearon que la cueva podría haber tenido forma de túnel por el cual habría corrido el viento, hipótesis que concuerda con las entrevistas y comunicaciones realizadas en esta investigación, pero que no ha podido ser comprobada empíricamente por la situación actual del sitio.

5. La cueva fue dinamitada, posiblemente durante la dictadura cívico-militar, por motivos poco claros.
Respecto al último punto, se recogieron, entre los vecinos, dos nuevas teorías de la razón de la destrucción del sitio. Algunos creen que fue dinamitada por los militares "porque tiene que haber gente adentro, muerta, pal' 73" (N. Soto, 2017), es decir, como producto de una situación de violación a los derechos humanos. Esto concuerda con el hecho de que Paine fue la zona con mayor porcentaje de detenidos-desaparecidos y ejecutados por habitante durante la dictadura y con que un profesor de la escuela de Chada, Cristian Víctor Cartagena Pérez, permanece desaparecido desde su detención el 18 de septiembre de 1973 (Corporación Nacional de Reparación y Reconciliación, 1996; Echeverría \& Bravo, 2019). Sin embargo, esta hipótesis no puede ser confirmada sin una excavación arqueológica.

Otra teoría afirma que la destrucción de Wayra Wasi habría formado parte del plan desarrollado, entre otros, por el Instituto Geográfico Militar para dinamitar el cerro Challay y liberar de smog a la Región Metropolitana. Esta última hipótesis es bastante aceptada por la gente del sector (Delgado, 2015; Esteban Fuentes, comunicación personal, 2017). 
Figura 4: a. Posible ubicación de Wayra Wasi destruida. b. Orificio para poner explosivo en el mismo sitio.

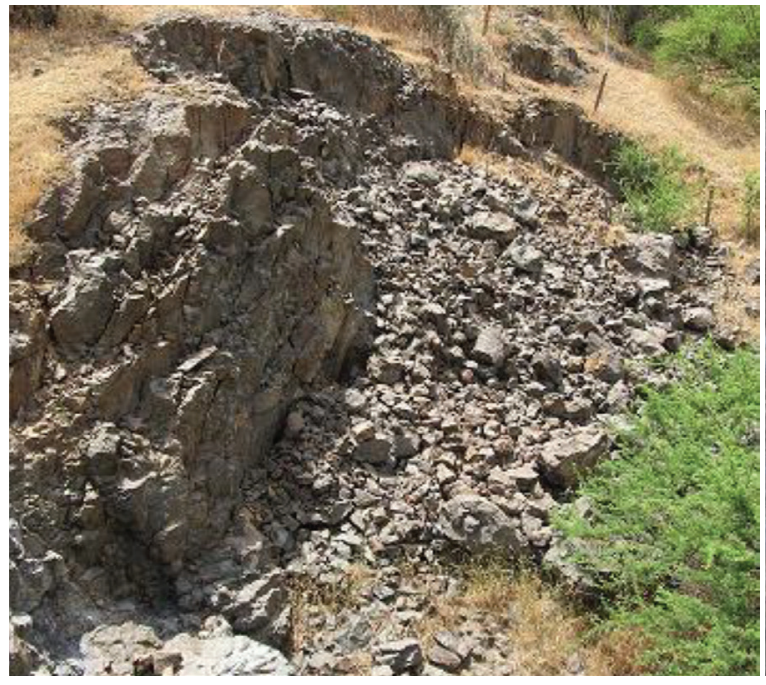

a.

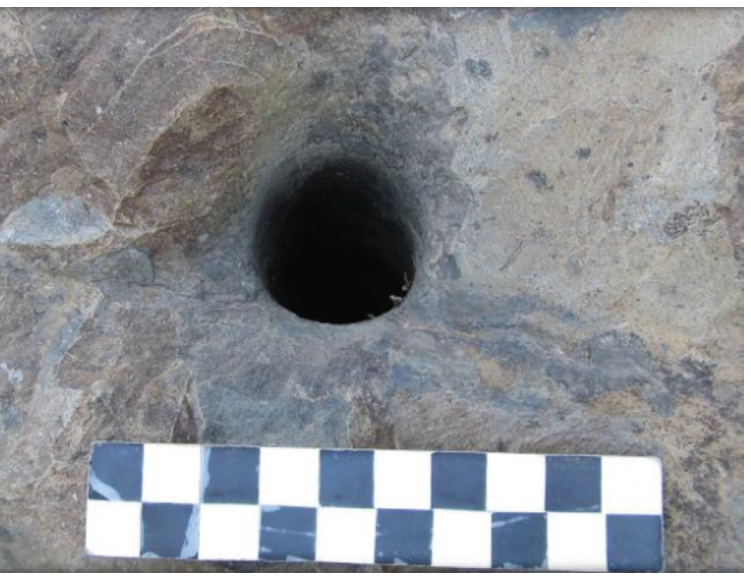

b.

Fuente: Ruano (2012).

Si el acercamiento etnográfico permite constatar que Wayra Wasi efectivamente existió, tal como señala Bibar, y que por ella corría un viento "bien recio", no es improbable que los nortinos se hubiesen mostrado "muy contentos" al encontrarla y hubiesen ritualizado el paisaje del sector mediante la veneración a la "casa del viento" (Stehberg \& Sotomayor, 2012). Y aunque se ha planteado que aún no es posible confirmar la asociación entre la construcción de las Ruinas de Chada y el culto a Wayra Wasi (Pavlovic et al., 2019), Bibar señala lo contrario al narrar que la edificación Inka se justificaría por la presencia de dicha cueva, algo que sostiene como testigo, ya que visitó personalmente el sector (Stehberg \& Planella, 1998).

Las observaciones arqueoastronómicas de Ruano (2012) refuerzan este punto al demostrar que desde una de las almenas o balcones del complejo arquitectónico y desde el ushnu en la cumbre del lugar se ve cómo el sol desaparece sobre la ladera norte del cerro Challay durante el solsticio de invierno. En otras palabras, para la fecha del Inti Raymi ("Fiesta del Sol" andina), que tiene una gran relevancia en el calendario Inka, el sol se pone justo encima de la ubicación estimada de Wayra Wasi si se observa desde las Ruinas de Chada (ver Figuras 3 y 5).

De esta manera, la evidencia apunta a pensar que Chada habría sido valorizado como un espacio de alto contenido simbólico debido a que "ahí se encontraba la casa donde habitaba el viento fuerte" (Odone, 1997, p. 192). La pregunta que surge, entonces, es la del significado que tuvo esta cueva o túnel para el Inka, más allá de la de ser un espacio importante. ¿Cuál fue la interpretación que el Tawantinsuyu hizo de este sitio que siglos después sería considerado un lugar de escondite, extracción minera, locura y excesos? Posiblemente nunca se sepa con exactitud, pero se pueden presentar hipótesis. 
Figura 5: Algunas fechas en las que desaparece el sol sobre el cerro Challay y sus montañas asociadas, vistas desde el complejo arquitectónico Ruinas de Chada, ladera poniente. Nótese que, durante el solsticio de invierno, 21 de junio, el sol se coloca sobre la ubicación estimada de Wayra Wasi.

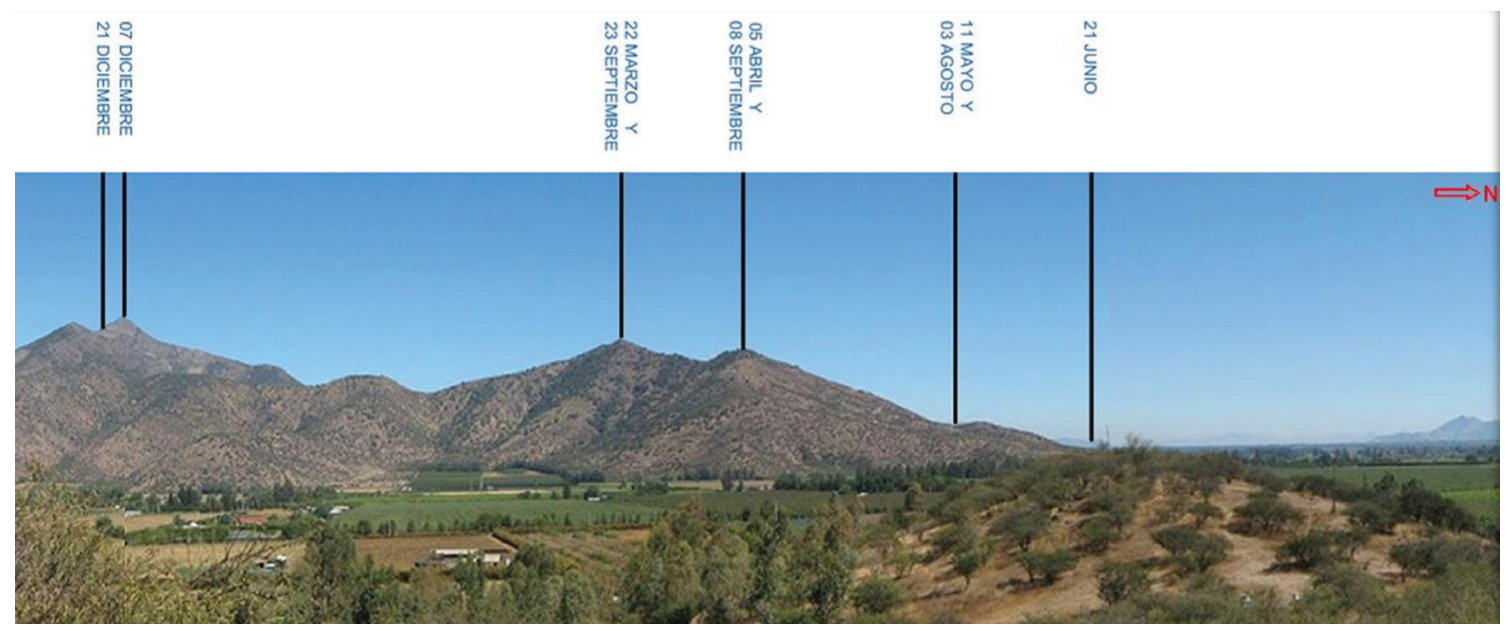

Fuente: Ruano (2012).

\section{Los oráculos andinos}

Ciertos elementos naturales y artefactos culturales, que para la cosmovisión moderna occidental son solo materiales inertes o se encuentran jerárquicamente muy por debajo del ser humano, para las comunidades andinas tenían y tienen un rol fundamental y vivo. Este es el caso de algunas formaciones rocosas, montañas o incluso antepasados momificados que poseían una fuerza que los animaba y sostenía. Y si bien estas waka tenían distintas jerarquías según las creencias de cada grupo, en la mayoría de ellos cumplían roles sociales muy importantes.

Una de las funciones que podían tener las waka locales era la oracular. El concepto "oráculo" tiene en sí una connotación propiamente europea y, por lo mismo, podría considerarse como poco aplicable para las socie- dades prehispánicas. Sin embargo, este término ha sido utilizado por diversos autores con el fin de establecer una relación entre el fenómeno oracular de la Europa clásica con el de la antigüedad andina. Marco Curatola, historiador, antropólogo y filósofo que ha estudiado en profundidad esta temática, llegó a la conclusión de que en Sudamérica existieron oráculos tal como se entendían en la antigua Grecia, "en el sentido más preciso y pleno del término" (Curatola, 2011, p. 15). Por lo tanto, este concepto puede postularse como un término válido que ha sido trabajo en las últimas dos décadas por numerosos autores del área andina, como Mariusz Ziólkowski, César Astuhuamán, Margarita Genitle y Lorenzo Huertas.

Ahora bien, ¿en qué consistían los oráculos andinos? Siguiendo a Curatola, la evidencia documental y arqueológica ha permitido sostener que cada ayllu, cada comunidad, tenía, 
antes de la conquista española, su propio oráculo. Estos podían ser piedras, cuerpos momificados (malquis) de líderes antepasados o paqarinas, que eran los lugares originarios de las comunidades, muchas veces cuevas. "Todas estas entidades sagradas y cualquier otro objeto, imagen o adoratorio identificado con seres y poderes extrahumanos, eran llamados genéricamente huacas (wak'a) y todos eran, por lo menos en potencia, oráculos" (Curatola, 2008, p. 17). A algunos de estos espacios o elementos habría acudido un líder religioso, o un cuerpo de "sacerdotes", para realizar consultas de predicción oracular a las divinidades con el fin de comunicar sus respuestas o interrogantes a los fieles (Curatola, 2011). No obstante, Lorenzo Huertas ha señalado que en algunos documentos "se encuentran mencionadas otras huacas oraculares que daban respuestas a la gente directamente, sin la necesidad de intermediarios" (2008, p. 268).

Para el período Inka, los principales oráculos habrían sido Pachacamac, Titicaca (en la isla del Sol), Catequil, Huanacauri y el templo de Qoricancha (en Cuzco). Si bien estos cumplieron un rol muy importante durante el periodo Tawantinsuyu, los oráculos ya tenían un papel medular en los Andes desde mucho antes como "una de las instituciones 'eje' de las sociedades complejas andinas, posiblemente desde las últimas fases del Precerámico (segunda mitad del III milenio a.C.)" (Curatola, 2008, p. 24).

Teniendo en cuenta lo anterior, cabe preguntarse por la relevancia de esta "institución" en los Andes. Primero, cumplió un rol clave al manifestarse mediante sitios que eran consultados tanto en situaciones cotidianas como anormales, pues era muy poco usual que las comunidades andinas tomaran decisiones sin el consejo previo de sus waka o sus ancestros (Spalding, 2008). Para Silvia Limón, "los oráculos fueron un importante elemento religioso que ejerció una gran influencia en la población y contribuyó al control social y político, a la par que proporcionaba soluciones a cuestiones como la salud y la producción" (2005, p. 22). Es decir, al mismo tiempo entregaban respuestas a las problemáticas de cada comunidad y servían al Tawantinsuyu como una forma de dominio, lo que habría apoyado su expansión y control de la población. Si a esto se le suma el hecho de que las poblaciones andinas realizaban procesiones hacia los oráculos más importantes, y que en algunos de estos se realizaban confesiones ${ }^{6}$, es posible afirmar, incluso, que dichos centros habrían sido lugares de almacenamiento de información, liderados por los "sacerdotes" del Inka, que ayudaban a saber lo que ocurría en las distintas regiones (Curatola, 2008).

El estudio de los oráculos andinos ha sido un tema trabajado y bien delineado en las últimas décadas. Sin embargo, las investigaciones se han centrado en los actuales territorios de Perú y Bolivia, en donde su presencia fue, quizá, más evidente. Para el extremo sur del Kollasuyu esta temática sigue pendiente y existe un enorme vacío investigativo. Por lo general, los arqueólogos y etnohistoriadores chilenos utilizan los conceptos de waka y "adoratorio" para referirse a los espacios y entidades de carácter sacro para el Inka. La noción de oráculo, en cambio, no es integrada conceptualmente (Pavlovic et al., 2012; Ruano, 2012; Moyano \& Bustamante, 2013; Stehberg, 2013; Cornejo, 2016; Stehberg et al., 2018; Moyano, 2018; Pavlovic et al., 2019, por mencionar algunos). 


\section{El culto a la cueva del viento}

Por lo expuesto, se plantea que Chada fue un espacio relevante dentro de la zona sur del Kollasuyu y más aún desde una perspectiva religiosa. Por ello, cabe preguntarse dónde estaban los oráculos $\mathrm{o}$, por lo menos, qué waka consultaban los líderes cuzqueños o diaguita-inka en esa localidad para cumplir con los objetivos señalados. Es en este ámbito que Wayra Wasi pudo haber cumplido un rol específico.

El cronista Bernabé Cobo, a inicios del siglo XVII, describió los ceques (líneas sagradas imaginarias) del sector del Cuzco. Entre ellos, señaló: "La octava, Guayra, es una quebrada de la Angostura, adonde contaban que se metía el viento. Hacíanle sacrificio cuando soplaban recios vientos" (1893, p. 32). Este fragmento fue recopilado por la historiadora Carolina Odone (1997) para destacar el simbolismo del viento en el sector de Angostura, donde se emplaza el valle de Chada, sin homologar este espacio al cercano al Cuzco. Al respecto, Stehberg y Planella (1998) señalan que la "guayravaci" citada por Bibar "podría representar una réplica de aquella situada en el área del Cusco [señalada por Cobo]; o viceversa, la del Cusco sería una copia de la casa del viento localizada en territorio chileno" (p. 167).

La creación de réplicas de las waka locales era algo frecuente en el Tawantinsuyu "y representaba el deseo de las autoridades cusqueñas de apropiarse simbólicamente de las guacas establecidas en las provincias" (Stehberg \& Planella, 1998, p. 167). Los planteamientos de estos autores indicarían que la cueva habría sido una waka de rango estatal conocida en la capital Inka. Ahora, ¿por qué se hacían sacrificios en ese lugar cercano al Cuzco? Se podría responder con la descripción de Cobo de otro espacio que el Inka también llamaba Guayra: "en ella se hacían sacrificios al viento para que no hiciese daño" (1893, p. 16).

De todo ello se deducen dos posibles significados del culto a Wayra Wasi: primero, como una waka replicada en relación con la del Cuzco, y segundo, como un lugar donde se hacían sacrificios para que el aire no hiciera daño "cuando soplaban recios vientos" (Cobo, 1893 , p. 32). Esto adquiere mayor sentido al considerar que "las waka eran adoradas por el temor y reverencia que podían suscitar entre los indígenas" (Galdames \& Díaz, 2015, p. 11). Es interesante mencionar que este sentimiento se condice con la visión que algunos grupos actuales tienen de las masas de aire. En el caso del noroeste argentino, por ejemplo, Mariano Bussi ha identificado comunidades que han sentido y sienten un profundo respeto -e incluso temor- hacia ciertos flujos aéreos que pueden traer consecuencias nefastas para la población (2015).

Para las sociedades andinas, las cuevas parecían tener una relevancia aún mayor que el viento, y es en este aspecto donde pareciera radicar gran parte de la trascendencia del sitio. El rol de las cuevas en los Andes ya ha sido discutido por los etnohistoriadores, quienes han destacado su vital importancia dentro del Tawantinsuyu como lugares de origen (Limón, 1990); esto es, como paqarinas donde se encontraría el nacimiento mítico de diferentes grupos culturales, entre ellos el Inka (Martínez, 2004). De esta manera, las cuevas cumplieron un papel muy relevante en el pasado de las comunidades, al ser uno de los lugares donde se originaba la vida, pero también en el futuro cíclico del mundo andino, con su rol como oráculos. 
A continuación, se describirán tres casos distintos que ilustran cómo pudo haber sido el culto a Wayra Wasi. El primero es un templo ubicado en el cerro Aconcagua, del departamento de Apurimac en Perú, que Silvia Limón identificó como un oráculo muy antiguo a partir de los escritos de Cieza de León y la Carta Annua de la Compañía de Jesús, de 1599:

La Carta Annua [...] la describe como una cueva en cuyo fondo había una protuberancia, detrás de la cual el demonio daba respuestas según lo que se le preguntara. Igualmente, detalla que en una concavidad de la caverna había una llama de plata que era objeto de culto. A este oráculo acudían, con gran devoción, individuos de tierras lejanas que le llevaban presentes para que el oráculo, a cambio, contestara lo que el donante quería saber, además de que prometía a sus peregrinos devotos salud y prosperidad para ellos y para sus ganados y sementeras (Limón, 2005, p. 19)

La referencia al demonio da cuenta de una divinidad no católica, que era visitada desde muy lejos para consultar inquietudes y tener salud, como en muchos de los oráculos andinos. A esta divinidad, que residía dentro de la cueva, representada posiblemente por una llama de plata y una "protuberancia", la gente ofrecía todo tipo de obsequios, como objetos de oro y plata, grandes cantidades de lana de colores, huesos de animales, "sabandijas" e incluso sacrificios humanos, según relatan los jesuitas, por ser uno de los principales oráculos de la zona (Limón, 2005). En este relato queda claro que las cuevas no solo podían ser oráculos, sino también cumplir un papel preponderante entre ellos, por lo que recibían todo tipo de ofrendas.

El segundo caso es un relato recopilado por Josep Barnadas sobre una gran cueva que seguía siendo visitada por los indígenas de la Villa Imperial de Potosí en pleno período colonial:
[...] un día a la semana iban como en procesión a adorar al demonio, que las más veces se les aparecía visible en figura horrible y espantosa; la quebrada tenía fatídicas peculiaridades: "pasando las gentes por allí, repentinamente se juntaban las dos peñas (que son altísimas) y matándolos a todos se tornaban a abrir" - "se levantaba un viento huracán tan espantoso que súbitamente les quitaban la vida y si no se las quitaba, en aquel punto los arrebataba y arrojaba encima de otras peñas que hay en sus contornos" (Barnadas, 1993, pp. 100-101. Las cursivas son originales).

De este fragmento se pueden destacar al menos tres elementos relevantes para el estudio de Wayra Wasi. Primero, el hecho de que se hicieran procesiones semanales hacia la cueva, tal como se peregrinaba a los oráculos prehispánicos, para adorar al "demonio" que ahí habitaba. Segundo, el vínculo entre este espacio subterráneo vivo y el viento, tal como en Chada. Por último, la relación que tenía el viento fuerte, junto al espacio en general, con la muerte. Esto recuerda la cita del cronista Cobo sobre los sacrificios que el Inka ofrecía al viento para que no hiciera daño y la descripción de Stehberg y Planella (1998) de que los vecinos de Wayra Wasi creían que esta se tragaba a la gente.

El último caso aparece en los documentos relacionados con una extirpación de idolatrías del siglo XVII en la provincia de Atacama recopilados por Victoria Castro (1993):

[...] los mas indios de aquella provincia tienen una cueba donde para sus ydolos y ydolatrias estavan cabezas de leones carneros de (f. 12) la tierra ay cus [cuys?].coca chicha. quilaPana y la yervacata todo lo qual tienen para ofrezer a los dichos ydolos [...] todos los ydolos que tenian que son desde el tiempo del inga (pp. 352-353. Las cursivas son originales). 
Nuevamente aparece una cueva en la que se realizaban ofrendas, desde tiempos del Inka, a una divinidad representada mediante "ídolos", esta vez con coca, chicha y animales. Victoria Castro (1993) plantea que los leones y camélidos señalados en el fragmento anterior podrían haber estado dibujados en la roca, lo que recuerda al cerro Challay. Según la gente del sector, en los cerros cercanos a Chada y Culitrín existe una serie de cuevas con dibujos, como se señalará a continuación. Por lo tanto, se podría pensar en una cierta similitud de culto entre ambas cuevas del Kollasuyu, la de Atacama y Wayra Wasi.

$\mathrm{Si}$ bien es necesario recalcar que no se pueden extrapolar por completo estas realidades propiamente andinas al caso del valle central de Chile, que es un área cultural distinta, estos tres ejemplos permiten ilustrar, de forma comparativa, ciertos elementos que el Inka podría haber implementado en el culto a Wayra Wasi, como las ofrendas rituales, las consultas oraculares, las procesiones y el temor o respeto al viento proveniente de una cueva. Igualmente, los tres casos presentados son solo algunos de los múltiples sitios similares al de Chada donde se han registrado adoraciones, sacrificios 0 consultas oraculares.

Precisamente, otro ejemplo es el gran centro oracular de Catequil, cuya construcción más importante "tenía el carácter de una cueva artificial" (Topic, 2008, p. 87). Luego de que Atahualpa destruyera este santuario, los restos de la figura que allí era adorada y consultada fueron "trasladados a una cueva ubicada en lo alto de un cerro, a fin de que Catequil pudiera seguir recibiendo el debido culto a hurtadillas de los cristianos" (Curatola, 2008, p. 46).
Por otro lado, Mariusz Ziólkowski (2008), luego de analizar numerosos oráculos de culto imperial asociados a los cerros, sostiene que las instalaciones donde se realizaban las actividades oraculares "no estaban situadas en las cumbres mismas o en lugares con un acceso particularmente difícil. En el caso concreto de Pariacaca, esta probablemente tenía lugar en una cueva situada en las laderas del cerro" (2008, p. 128). La descripción de este último oráculo coincide con el de Wayra Wasi, sitio de fácil acceso ubicado en la ladera del cerro Challay.

\section{Las cuevas del Challay}

Al consultar por una cueva en específico durante la etapa etnográfica de esta investigación, la gente de Chada, Culitrín y Hospital recordó otras cuevas ubicadas en el cerro Challay y sus montañas aledañas que no han sido referenciadas en publicaciones anteriores. A continuación, y a modo de referencia, se mencionan algunas de las memorias asociadas a seis de estas cuevas, cavernas o túneles.

Según la información recopilada en terreno, existirían dos cavernas contiguas, una más grande que la otra, en el sector poniente del Challay, hacia Hospital. ¿Sería o serían acaso la segunda salida del supuesto túnel de Wayra Wasi? No es posible determinarlo por ahora. Una tercera cueva, según Néstor Soto, fue creada para la extracción minera. "Arriba hay una mina de oro donde están las... hay una mina de oro que está abandonada hace como cuatro años atrás la trabajaron, y el caballero estuvo como siete meses y la abandonó, porque decía que le daba poco oro" (N. Soto \& E. Fuentes, 2017). Quizá refiriéndose al mismo 
espacio, u otro similar, el agricultor de Hospital, Óscar Pinto (2017), señaló:

Mire, esa, esa cueva la hizo un mismo [...] el mismo gallo que quería sacar algo de ahí, la hizo él mismo. Llegó a tal, a tal profundidad pa' abajo, no sé a cuántos metros tendrá, pero ahí le salió agua y hasta ahí no más llegó, no pudo avanzar más y no consiguió nada. Nada más que la muerte consiguió ahí, porque falleció también.

Probablemente sobre la misma persona, el profesor Esteban Fuentes (2017) recuerda:

El otro, es la historia del este que empezó a cavar a cavar por una, por una mina de oro que había ahí en... Ah, en la vuelta de Culitrín. Sí, en la vuelta de Culitrín. Sí. Y bueno, y se falleció el caballero. Ya ¿y qué? ¿Encontró algo o no? No, no encontró nada, pero por varios años escavó, escavó (En cursiva las intervenciones de Esteban Fuentes y sin ella los comentarios de Néstor Soto).

Por lo tanto, más allá de si los tres entrevistados están hablando del mismo espacio minero o no, existe una memoria común asociada al cerro Challay como un lugar de supuestos tesoros o riquezas, a los que se podría acceder mediante excavaciones, aunque aún no hayan sido encontrados. Asimismo, los esfuerzos por buscar riquezas en el Challay se vincularían con la muerte.

Un cuarto espacio señalado por los entrevistados, ubicado cerca de la cima del Challay, sería una cueva con dibujos de un sol y una araña, cuya procedencia prehispánica o contemporánea aún no está definida (Néstor Soto, comunicación personal, 2017). Ahora bien, esta no sería la única caverna con dibujos alrededor del cerro. Una quinta, llamada "cuevita del mono" por Esteban Fuentes, estaría ubicada en Culitrín, no lejos de Wayra Wasi. "Le robaron los dibujos. Yo, yo alcancé a ver los petroglifos, los alcancé a ver. Ya cuando fui por segunda vez ya no, no habían" (N. Soto \& E. Fuentes, 2017. En cursiva las intervenciones de Esteban Fuentes y sin ella las de Néstor Soto). Ahí mismo, la cuñada de Esteban Fuentes "vio unos monitos [...] en vivo y en directo. $Y$ se escabullían" ( $\mathrm{N}$. Soto \& E. Fuentes, 2017. En cursiva las intervenciones de Esteban Fuentes).

Una última cueva identificada en el Challay, a la que también se le atribuyen significados especiales, posiblemente de larga data, es la "cueva de la vieja". A pesar de que Stehberg y Planella (1998) sugirieron que este sitio podría ser la segunda salida de Wayra Wasi, los agricultores chaínos Miguel Caviere y Cristián Sepúlveda aseguran que no sería una cueva propiamente tal, sino más bien una formación rocosa:

La parte que llamaban la cueva de la vieja. Ese era, los antiguos que llamaban cuando, como le explicaba yo que cuando era bueno el año corría el agua por la cueva de la vieja [...] Esa es toda esa piedra que está al fondo en Challay [...]. Es por la saturación del suelo que, ya cuando eran buenas las lluvias se saturaba el suelo y comenzaba a escurrir el agua eh... cinco, seis días seguidos, se notaba, o sea, se veía que caía el agua por encima de la piedra (C. Sepúlveda \& M. Caviere, 2017. En cursiva los comentarios de Miguel Caviere y sin ella los de Cristián Sepúlveda)

De esta manera, en las memorias de ambos agricultores, la llamada "cueva de la vieja" por "los antiguos" era un indicador de los buenos años para las cosechas en relación con las lluvias. Óscar Pinto mencionó un lugar de características similares en el sector de Hospital, la "piedra azul":

Había una caída de agua que caía ahí, y esa agua se consumía en cierta parte, que se llama la piedra azul. 
La piedra azul se llama, que en el tiempo de invierno, cuando llovía mucho [...] el agua caía ahí y duraba, duraba el agua cayendo ahí duraba diez días, mínimo, diez días, quince días a veces, y caía un chorro que se veía lindo (O. Pinto, 2017).

De esta manera, es posible sostener que existen distintos tipos de memorias, con contenidos diversos, asociados a una pluralidad de espacios de cuevas, cavernas o minas alrededor de todo el cerro Challay, tanto en su ladera norte hacia Culitrín, como en el sector de Chada, al oriente, y Hospital, al poniente. Estos sitios, distintos de Wayra Wasi, habrían tenido igualmente un gran simbolismo para las comunidades de la zona al ser vinculados con tesoros, muertes, dibujos o petroglifos, y lluvias ${ }^{8}$.

Figura 6: Cerro Challay visto desde el poniente, sector Hospital, Colonia Kennedy. En un círculo se indica la ubicación de la "piedra azul" (Óscar Pinto, comunicación personal, 2017).

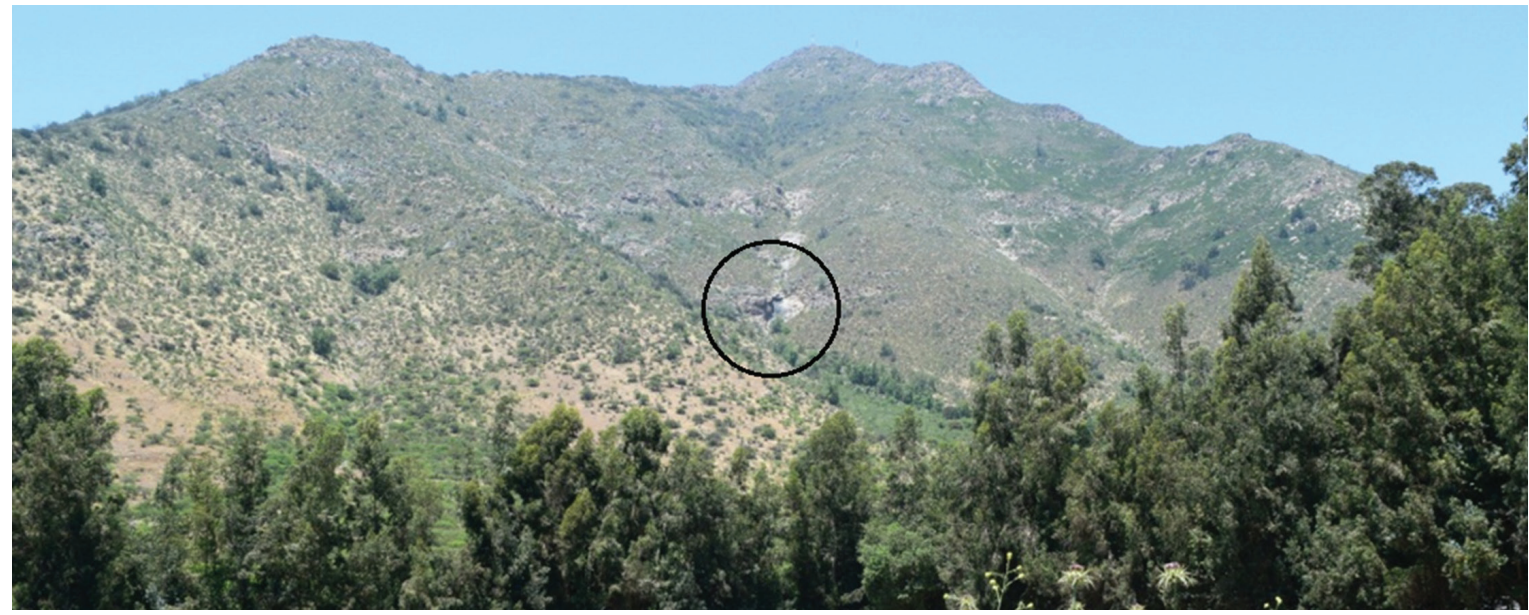

Fuente propia, 2017.

\section{Discusión y conclusiones}

En 1558 Gerónimo de Bibar escribió que cerca de la actual Angostura de Paine, al sur de la Región Metropolitana, el pueblo Inka encontró una boca y cueva por la cual salía un viento "bien recio". Esto los alegró, pues habían encontrado a "guayravaci" (Wayra Wwasi), la casa del viento, lo que los condujo a construir un poblado en el sector. Esta fue la información que siguieron los arqueólogos Rubén Stehberg, María Teresa Planella y Hans Niemeyer para viajar a Chada en la década de 1990 y que los llevó a excavar el complejo arquitectónico Ruinas de Chada, dos sitios habitacionales de la cultura Aconcagua, y a dar las primeras noticias sobre Wayra Wasi: la cueva había sido destruida (Planella \& Stehberg, 1997; Stehberg et al., 1998; Stehberg \& Planella, 1998).

De la misma manera, la crónica de Bibar fue el punto de inicio de una nueva investigación realizada en Chada, Culitrín y Hospital en 2017, centrada en la antigua cueva y reforzada 
por una segunda etnografía en 2018 y nuevas prospecciones en 2019. De esta forma, se sintetizaron las investigaciones arqueológicas y etnohistóricas realizadas con anterioridad y se llevó a cabo un estudio de campo centrado en las distintas memorias asociadas al espacio. A través de esta metodología interdisciplinaria, que vinculó elementos de la antropología y la microhistoria, se pudo recabar información relevante sobre un sitio de muy difícil acceso arqueológico, como lo es esta cueva dinamitada.

Los resultados de la investigación demostraron que Wayra Wasi no solo existió, sino que permanece viva en los recuerdos de los pobladores de Chada y Culitrín y, aunque por ella efectivamente habría sonado el viento con fuerza, sus significados asociados, en el presente, son múltiples y dependen de la subjetividad de cada entrevistado. Mientras algunos pobladores afirmaron que Wayra Wasi era una cueva por donde pasó Manuel Rodríguez y que luego fue la residencia de un sacerdote que cayó en la locura por vivir ahí, otros sostuvieron que los hombres iban al lugar a realizar apuestas y tener conductas inapropiadas. Igualmente, algunos contaron que la cueva había sido utilizada para la extracción de minerales, o que era temida porque se tragaba a la gente, mientras que un poblador señaló que habría sido llamada "chiflón del diablo" por los indígenas porque allí el viento "bufaba como toro". Finalmente, se recopiló una memoria mixta que interpretaba lo escrito por Bibar a partir de ciertos fenómenos atmosféricos de Chada en que la unión de temperaturas cálidas y frías generaría una "brisa permanente", lo que explicaría la presencia del viento.

En el presente estudio se plantea, además, la posibilidad de que Wayra Wasi hubiese tenido la forma de un túnel por el cual atravesaba el viento, tal como plantearon Stehberg y Planella (1998) en un primer momento. Además, se postula que la cueva fue dinamitada posiblemente durante el período de la dictadura iniciado en 1973. Con esto se terminó con un espacio de gran significado local y prehispánico, que habría tenido un valor patrimonial y arqueológico invaluable, y se puso fin a la afirmación de Bibar (1952): "una boca y cueva, la cual está hoy en día y estará" (p. 138).

En cuanto a los significados que Wayra Wasi pudo haber tenido para el Inka y su ocupación en el extremo sur del Tawantinsuyu, se identificaron las siguientes posibilidades:

1. Haber sido interpretada como una réplica de una waka importante en las cercanías del Cuzco, que también se encontraba en una angostura geográfica por donde "se metía el viento" y era venerada, teniendo así un alcance estatal.

2. Haberse constituido como un lugar ritual de sacrificios animales para pedir que el viento no hiciera daño cuando soplaba con fuerza. Esto podría tener relación con las creencias andinas en divinidades que provocaban vientos recios y huracanes, como Wayra Tata.

3. Haber sido un lugar de consulta oracular, una waka capaz de predecir eventos futuros. Un espacio de veneración y peregrinación. Esto habría permitido al Tawantinsuyu controlar de mejor manera a la población local, mientras le daba la posibilidad a esta de conocer el futuro de sus cosechas, pedir consejos, predecir eventos y rogar por salud y protección. Esta idea adquiere fuerza si se considera la existencia de divinidades 
andinas relacionadas con la vida y la fertilidad, que podían provocar vientos fuertes, como Wari e Illapa.

Estas tres interpretaciones no son excluyentes entre sí, sino que pueden entrelazarse y complementarse para dotar de un mayor significado al espacio sagrado de Chada y Culitrín. Ello explicaría por qué el cronista Bibar fue testigo personal de este sector: el ser tan significativo para los indígenas habría empujado al cronista a visitarlo.

La mayoría de las investigaciones sobre oráculos se han desarrollado en los actuales territorios de Perú y Bolivia, mientras que para el extremo sur del Kollasuyu este fenómeno prácticamente no ha sido estudiado. Lo que aquí se postula es que es poco probable que estos organismos no hayan existido en la región, por lo que la falta de información al respecto se podría deber simplemente a que los sitios oraculares no han sido destacados desde esa perspectiva. Por lo tanto, como una manera de avanzar en esa dirección, se presentó el caso de Chada como un lugar privilegiado para un estudio de este tipo, debido al carácter religioso de la arquitectura Inka del sector y de la existencia de otras cuevas similares que funcionaban como oráculos a lo largo del Tawantinsuyu. No obstante, la falta de documentos históricos que caractericen a Wayra Wasi dificulta obtener resultados más concluyentes.

Se plantea, como primera hipótesis, entonces, que tal como ocurría en otras cuevas, Wayra Wasi podría haber sido un oráculo Inka al que acudían peregrinaciones de pobladores de los alrededores, e incluso de más lejos, para pedir consejos, predecir eventos, rogar por salud y protección, o para que el viento no les hiciera daño. A su interior podría haber existido una(s) figura(s) o dibujo(s), a los cuales se habría rendido culto y realizado ofrendas de animales, chicha u otros. Quizá la fecha más importante para celebrar o hacer rogativas al viento que habitaba y rugía en la cueva era el Inti Raymi, solsticio en el cual Inti, la divinidad solar, se escondía encima de la Wayra Wasi al atardecer si se miraba desde el observatorio y waka del lugar, denominado actualmente Ruinas de Chada.

Las festividades fueron uno de los mecanismos utilizados por los gobernantes cuzqueños para controlar a las poblaciones locales. Y si se tiene presente que en la cuenca del Maipo "estas actividades se desarrollaron de preferencia en cumbres de cerros apropiadas y resemantizadas ideológicamente por el Tawantinsuyu mediante el uso de la arquitectura y su correlación visual y/o espacial con cumbres sacralizadas" (Pavlovic et al., 2019, p. 45), es posible sostener que las celebraciones como el Inti Raymi eran de mucha relevancia para el Inka en el sector.

Finalmente, a partir de lo planteado en este artículo, se abren, por lo menos, tres nuevas líneas de investigación para el futuro. Primero, el rol de los oráculos andinos y la integración de su culto en el extremo sur del Kollasuyu. Segundo, estudios sobre las demás cuevas del cerro Challay, que han sido ignoradas en los trabajos preexistentes, y que pueden entregar información muy valiosa, como posibles pinturas rupestres o petroglifos. Tercero, una investigación que cuente con el financiamiento suficiente como para contratar maquinaria pesada que remueva el contenido dinamitado de Wayra Wasi, revise este material y permita realizar una excavación arqueológica en el sitio. Así se podrían comprobar o refutar las hipótesis aquí propuestas. 


\section{Agradecimientos}

Este artículo fue escrito en memoria de don Guillermo Soto, sabio chaíno, y don Rodolfo Sepúlveda, quienes fallecieron antes de poder entrevistarlos. Que su memoria permanezca viva a través de Bibiana, Celia, Cristián y todos sus hijos.

Agradezco a Carolina Odone, quien guio este trabajo, junto a todos los procesos etnográficos realizados en el sector. A Nicolás Ruano, por su apoyo, comentarios y compañía al visitar Chada, y a Óscar Toro, por sus recomendaciones y contactos.

A José Miguel Echeverría, el primero en acompañarme a buscar a Wayra Wasi, y a los verdaderos protagonistas de este artículo: Esteban Fuentes, Óscar Pinto, Cristián Sepúlveda, Néstor Soto y Miguel Caviere. A Mario Salas, ex director de la escuela Senderos de Culitrín; Débora Ruiz-Tagle y María Eugenia Oliva, de la escuela Mundo Infantil Ruta Sur; Marcela Morales, Johana Pinto, Celia y Bibiana Soto, de la escuela Javier Eyzaguirre Echaurren, y Belarmino Trujillo, cuyos testimonios no aparecen aquí, pero fueron de vital importancia.

A Carla Bravo, incansable compañera de terreno; Catalina Jeanneret, por sus comentarios y apoyo; Jorge Ragas, por leer y comentar la investigación, y a Sabino Cabezas, Manuel Ortiz y Luisa Antonia Bozo, guardianes de las memorias chaínas.

\section{Notas}

${ }^{1}$ La etnografía se realizó en el marco del curso "Recordar, registrar e historiar memorias indígenas. Propuesta de ejercicios de investigación", a cargo de la profesora María Carolina Odone, Pontificia Universidad Católica de Chile, 2017. Los resultados de esta investigación, junto a la interpretación simbólica de Wayra Wasi, fueron presentados en el VI Congreso de Estudiantes de Historia, el 24 de octubre de 2018.

${ }^{2}$ Las entrevistas citadas en el artículo corresponden a los siguientes lugares y fechas: Óscar Pinto, 25 de octubre de 2017, Las Vertientes, Hospital; Cristián Sepúlveda y Miguel Caviere, 13 de noviembre de 2017, Chada; Néstor Soto y Esteban Fuentes, 18 de octubre de 2017, Chada.

${ }^{3}$ Este concepto es escrito también como "huaca" o "guaca", y es una derivación del quechua wak'a, que define, para las poblaciones andinas, un lugar o ente sagrado.

${ }^{4}$ Ex director de la escuela municipal de Chada "Javier Eyzaguirre Echaurren".

${ }^{5}$ Los vecinos que hicieron referencia al escrito de Bibar parecieran

no haber leído su crónica directamente, sino más bien la recopilación que han hecho de él autores contemporáneos. Esto se postula ya que tanto el agricultor Cristián Sepúlveda como la directora de la escuela Mundo Infantil Ruta Sur tenían en su posesión el artículo de la historiadora Carolina Odone (1997), titulado "El valle de Chada: La construcción colonial de un espacio indígena de Chile central", al que la directora llamó "su Biblia". En cambio, ninguno de los dos tenía en su propiedad la crónica de Bibar.

${ }^{6}$ Un caso bastante conocido es el oráculo de la Isla del Sol, en el que los peregrinos que llegaban a consultar sus dudas debían pasar por un proceso de purificación y de confesión antes de acercarse a la waka del lugar.

${ }^{7}$ Chilenismo usual en los sectores rurales de Chile que hace referencia a una persona.

${ }^{8}$ La visita a estos sitios, que debía realizarse a fines de 2019 , se vio interrumpida, hasta la fecha, por el denominado "Estallido Social" ocurrido en Chile y la posterior pandemia del COVID-19. 


\section{Referencias bibliográficas}

Barnadas, J. M. (1993). Idolatrías en Charcas (1560-1620): Datos sobre su existencia como paso previo para la valoración del tema de su extirpación. En Ramos, G. \& Urbano, H. (Eds.), Catolicismo y extirpación de idolatrías: Siglos XVI-XVIII. Charcas, Chile, México, Perú (pp. 89-105). Cuzco: Centro de Estudios Regionales Andinos "Bartolomé de Las Casas".

Bibar, G. (1952). Crónica y relación copiosa y verdadera de los reynos de Chile. Santiago: Fondo Histórico y Bibliográfico José Toribio Medina.

Bussi, M. (2015). Estar aireado: Flujos aéreos, cuerpos y vuelcos en Los Castillos, Catamarca. Estudios Sociales del NOA, 16, 87-106.

Cáceres, A. (2006). Narrativa quechua del Tawantinsuyu. Buenos Aires: Colihue.

Caro, P. (2017). Diseños diaguita en la cerámica en la cuenca del Maipo-Mapocho en el Período Tardío. (Memoria inédita para obtener el título de arqueóloga). Universidad de Chile, Santiago.

Castro, V. (1993). Un proceso de extirpación de idolatrías en Atacama, siglo XVII En Ramos, G. \& Urbano, H. (Eds.), Catolicismo y extirpación de idolatrías: Siglos XVI-XVIII. Charcas, Chile, México, Perú (pp. 347-366). Cuzco: Centro de Estudios Regionales Andinos "Bartolomé de Las Casas".

Cobo, B. (1893). Historia del nuevo mundo. Vol. 4. Sevilla: Impresora de E. Rasco.

Cornejo, L. (2001). Los Inka y sus aliados Diaguita en el extremo austral del Tawantinsuyu. En Aldunate, C. \& Cornejo, L. (Eds.), Tras la huella del Inka en Chile. Santiago: Museo Chileno de Arte Precolombino, Banco de Santiago.

(2014). Sobre la cronología del inicio de la imposición cuzqueña en Chile. Estudios Atacameños, 47, 101-116.

(2016). La tierra de las cuatro estaciones. Prehistoria de la Zona Central. En Chile milenario. Santiago: Museo Chileno de Arte Precolombino.

Cornejo, L. \& Saavedra, M. (2018). El centro político inka en el extremo austral del Tawantinsuyu (Chile Central). Boletín del Museo Chileno de Arte Precolombino, 23(1), 133-158.

Cornejo, L. \& Sanhueza, L. (2011). Caminos que cruzan la cordillera: El rol del paso del Maipo en la ocupación de la cordillera en Chile Central. Revista Chilena de Arqueología 23, 101-122.

Corporación Nacional de Reparación y Reconciliación (1996). Informe de la Comisión Nacional de Verdad y Reconciliación. Santiago: Andros Impresores.

Curatola, M. (2008). La función de los oráculos en el Imperio inca. En Curatola, M. \& Ziólkowski, M. (Eds.), Adivinación y oráculos en el mundo andino antiguo (pp. 15-69). Lima: Pontificia Universidad Católica del Perú.

(2011). ¿Fueron Pachacamac y los otros grandes santuarios del mundo andino antiguo verdaderos oráculos?: Una aproximación comparativa. Diálogo Andino, 38, 5-19.

(2012). Los cinco sentidos de la etnohistoria. Memoria
Americana, 20(1), 61-78.

Delgado, F. (2015). 3 ideas descabelladas que alguna vez se propusieron para descontaminar Santiago. Biobiochile.cl, 22 agosto. Recuperado de https://www.biobiochile.cl/noticias/2015/08/22/3-ideasdescabelladas-que-alguna-vez-se-propusieron-para-descontaminarsantiago.shtml

Dillehay, T. (2003). El colonialismo inka, el consumo de chicha y los festines desde una perspectiva de banquetes políticos. Boletín de Arqueología PUCP, 7, 355-363.

Echeverría, J. F. (2019). Marginalidad, discriminación y pobreza en perspectiva histórica: Estudio de caso del campamento Ribera del río en Talagante. Revista CIS, 16(27), 49-67.

Echeverría, J. F. \& Bravo, C. (2019). Memorias en conflicto, memorias en consenso: Estudio interdisciplinario de los cambios en el campo durante el siglo XX a una escala local: el caso de Chada. Notas Históricas y Geográficas, 23, 85-121.

Galdames, L. \& Díaz A. (2015). Piedra en la piedra, ¿el hombre dónde estuvo?: Percepción y significado de la piedra en la geografía sagrada de las sociedades andinas. Runa, 36(2), 5-23.

Geertz, C. (1992). La interpretación de las culturas. Barcelona: Gedisa.

Ginzburg, C. (2008). El queso y los gusanos: El cosmos según un molinero del siglo XVI. Barcelona: Península.

Huertas, L. (2008). Los oráculos en la historia andina (siglos XV-XVII). En Curatola, M. \& Ziólkowski, M. (Eds.), Adivinación y oráculos en el mundo andino antiguo (pp. 251-272Lima: Pontificia Universidad Católica del Perú.

Limón, S. (1990). Las cuevas y el mito de origen: Los casos inca y mexica. México: Consejo Nacional para la Cultura y las Artes. (2005). Oráculos y adivinación en los Andes: Su significado político-religioso. Mitológicas, 20, 9-24.

López, A. (2015). La huaca de Chada y la cueva de Culitrín: Pasado. Serie Rutas de Nuestra Geografía Sagrada. Biobiochile.tv. Video. Recuperado de https://www.youtube.com/watch?v=uAXuN_ WzF6A.

Man, R. (2013). La microhistoria como referente teóricometodológico: Un recorrido por sus vertientes y debates conceptuales. Historia Actual Online, 30, 167-173.

Manríquez, V. (2002). Purum Aucca, «Promaucaes»: De significados, identidades y etnocategorías: Chile central, siglos XVI-XVIII. Boletín de Arqueología PUCP, 6, 337-354.

(1999). El término Ylla y su potencial simbólico en el Tawantinsuyu: Una reflexión acerca de la presencia inca en Caspana (río Loa, desierto de Atacama). Estudios Atacameños, 18, 107-118.

Marsh, E. (2016). ¿Cuándo llegaron los Incas a Mendoza?: Una reevaluación de los fechados radiométricos mediante un modelo bayesiano. Actas del XIX Congreso Nacional de Arqueología Argentina (pp. 1906-1913). San Miguel de Tucumán: Facultad de Ciencias Naturales, Instituto Miguel Lillo, Universidad Nacional de Tucumán. 
Martínez, J. L. (2004). Discursos de alteridad y conjuntos significantes andinos. Chungara, Revista de Antropología Chilena, 36(2), 505-514.

Medinacelli, X. (2012). Bertonio y el mito de Tunupa. Ciencia y Cultura, 28, 133-151.

Moyano, R. (2016). El ushnu como observatorio lunar al sur del Trópico de Capricornio. Xama, 24-29, 91-110.

(2018). "De noche también sale el Sol”: Arqueoastronomía y ciclos lunares en los Andes del Collasuyu. Cuadernos del Instituto Nacional de Antropología y Pensamiento Latinoamericano. Series Especiales, 6(1), 58-83.

Moyano, R. \& Bustamante, P. (2013). Cerro Wangüelen: Obras rupestres, observatorio astronómico-orográfico Mapuche-Inca y el sistema de ceques de la cuenca de Santiago. Rupestreweb. Arte Rupestre en América Latina. Recuperado de http://www.rupestreweb. info/cerrowanguelen.html

Odone, M. C. (1997). El valle de Chada: La construcción colonial de un espacio indígena de Chile central. Historia, 30, 189-209.

Olivera, S. (2016). Evaluación de aversión al riesgo de los productores de Cerro Blanco en Calana-Tacna. (Tesis inédita para optar al título de ingeniero en economía agraria). Universidad Nacional Jorge Basadre Grohmann, Tacna.

Pascual, D., Martínez, A., Pavlovic, D., Dávila, C., Cortés, C., Albán, M. \& Fuenzalida, N. (2018). Queros de cerámica y la presencia del Tawantinsuyu en la cuenca de los ríos Aconcagua y Mapocho, extremo sur del Collasuyu. Boletín del Museo Chileno de Arte Precolombino, 23(1), 116-132.

Pavlovic, D., Sánchez, R., Pascual, D., Martínez, A., Cortés, C., Dávila, C. \& La Mura, N. (2019). Rituales de la vida y de la muerte: Dinámicas de interacción entre el Tawantinsuyu y las poblaciones locales en la cuenca del Maipo-Mapocho, Chile central. Estudios Atacameños, 63, 43-80.

Pavlovic, D., Troncoso, A., Sánchez, R. \& Pascual, D. (2012). Un tigre en el valle: Vialidad, arquitectura y ritualidad incaica en la cuenca superior del río Aconcagua. Chungara, Revista de Antropología Chilena, 44(4), 551-569.

Planella, M. T. \& Stehberg, R. (1997). Intervención Inka en un territorio de la cultura local Aconcagua de la zona Centro-Sur de Chile. Tawantinsuyo, 3, 58-78.

Ricoeur, P. (2004). La memoria, la historia, el olvido. Buenos Aires: Fondo de Cultura Económica.

Rostworowski, M. (2007). Estructuras andinas del poder: Ideología religiosa y política. Lima: Instituto de Estudios Peruanos.

Ruano, N. (2012). Arqueoastronomía Inca en el interfluvio Maipo-Cachapoal. (Tesis inédita para optar al título de arqueólogo). Universidad Internacional SEK, Santiago.

Silva, E., Silva, C., La Mura, N., Fuenzalida, N. \& Brinck, A. (2017). Sentidos del patrimonio de los sitios arqueológicos Ruinas de Chada y Pucará de Chena (río Maipo, Chile central): Historia local y entorno social. Intersecciones en Antropología, 18(2), 169-179.

Silva, O. (1985). La expansión incaica en Chile: Problemas y reflexiones. Boletín del Museo Arqueológico de la Serena. Actas del IX Congreso Nacional de Arqueología, 8, 321-344.

Spalding, K. (2008). Consultando a los ancestros. En Curatola, M. \& Ziólkowski, M. Adivinación y oráculos en el mundo andino antiguo (pp. 273-292). Lima: Pontificia Universidad Católica del Perú.

Stehberg, R. (1995). Instalaciones incaicas en el norte y centro semiárido de Chile. Santiago: Dirección de Bibliotecas, Archivos y Museos.

(2013). Caminos, guacas y el reducto fortificado de cerro El Peral: Instalaciones para el control inca del paso de Chada, Chile central. Boletín del Museo Nacional de Historia Natural, 62, 129-146.

Stehberg, R., Gatica, C. \& Torrijos, F. (2018). Habitantes del Mapocho sacralizan la Quebrada de Ramón, Santiago. En Estudios de arqueología, historia, filosofía y ciencias sociales en homenaje a Mario Orellana Rodríguez (60 años de vida académica y científica) (pp. 109-172). San Pedro de Atacama: Ediciones del Desierto, Corporación de Desarrollo de las Ciencias Sociales, Sociedad Chilena de Arqueología.

Stehberg, R. \& Planella, M. T. (1998). Reevaluación del significado del relieve montañoso transversal de "La Angostura" en el problema de la frontera meridional del Tawantinsuyu. Tawantinsuyu, 5, 166-169.

Stehberg, R., Planella, M. T. \& Niemeyer, H. (1998). Complejidad arquitectónica de las ruinas prehispánicas de Chada en la antigua ruta entre los ríos Maipo y Cachapoal. Xama, 6(11), 53-64.

Stehberg, R. \& Sotomayor, G. (2012). Mapocho incaico. Boletín del Museo Nacional de Historia Natural, 61, 85-149.

Stern, S. (2009). Recordando el Chile de Pinochet en vísperas de Londres 1998. Santiago: Universidad Diego Portales.

Topic, J. (2008). El santuario de Catequil: Estructura y agencia: Hacia una comprensión de los oráculos andinos. En Curatola, M. \& Ziólkowski, M. (Eds.), Adivinación y oráculos en el mundo andino antiguo (pp. 71-95). Lima: Pontificia Universidad Católica del Perú.

Toro, O., Olea, J., Gallardo, G. \& Castillo, G. (2015a). Arqueología en el valle de Chada: Una perspectiva regional. Santiago: Grafic Suisse.

Grafic Suisse.

(2015b). Chada: Patrimonio, territorio e identidad. Santiago:

Yauri, M. (2016). Deidades panandinas en el Perú antiguo en el Callejón de Huaylas (Ancash) [Los dioses de Pumacayán]. Scientia 18(18), 59-70.

Ziółkowski, M. (2008). Coropuna y Solimana: los oráculos de Condesuyos. En Curatola, M. \& Ziólkowski, M. (Eds.), Adivinación y oráculos en el mundo andino antiguo (pp. 121-159). Lima: Pontificia Universidad Católica del Perú. 